\title{
Satisfaction with life and psychological distress during the COVID-19 pandemic: An Egyptian online cross-sectional study
}

\begin{tabular}{|c|c|}
\hline \multicolumn{2}{|l|}{$\begin{array}{l}\text { Authors: } \\
\text { Ahmed H. El }\end{array}$} \\
\hline \multicolumn{2}{|c|}{$\begin{array}{l}\text { Affiliations: } \\
\text { 'Department of Psychiatric } \\
\text { and Mental Health Nursing, } \\
\text { Faculty of Nursing, Mansoura } \\
\text { University, Mansoura, Egypt }\end{array}$} \\
\hline \multicolumn{2}{|c|}{$\begin{array}{l}{ }^{2} \text { Department of Paediatric } \\
\text { Nursing, Faculty of Nursing, } \\
\text { Beni-Suef University, } \\
\text { Beni-Suef, Egypt }\end{array}$} \\
\hline \multicolumn{2}{|c|}{ 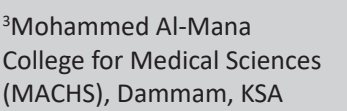 } \\
\hline \multicolumn{2}{|c|}{$\begin{array}{l}{ }^{4} \text { Department of } \\
\text { Gerontological Nursing, } \\
\text { Faculty of Nursing, Mansoura } \\
\text { University, Mansoura, Egypt }\end{array}$} \\
\hline \multicolumn{2}{|c|}{$\begin{array}{l}{ }^{5} \text { Department of Paediatric } \\
\text { Nursing, Faculty of Nursing, } \\
\text { Mansoura University, } \\
\text { Mansoura, Egypt }\end{array}$} \\
\hline \multicolumn{2}{|c|}{$\begin{array}{l}{ }^{6} \text { Department of Public Health } \\
\text { and Preventive Medicine, } \\
\text { Faculty of Medicine, } \\
\text { Mansoura University, } \\
\text { Mansoura, Egypt }\end{array}$} \\
\hline \multicolumn{2}{|c|}{$\begin{array}{l}{ }^{7} \text { Hamad Medical Corporation } \\
\text { (HMC), Doha, Qatar }\end{array}$} \\
\hline \multicolumn{2}{|c|}{$\begin{array}{l}{ }^{8} \text { Surgical Specialty Center } \\
\text { (SSC), Doha, Qatar }\end{array}$} \\
\hline \multicolumn{2}{|c|}{$\begin{array}{l}\text { Corresponding author: } \\
\text { Ahmed El-Monshed, } \\
\text { ahmed_elmonshed@mans. } \\
\text { edu.eg }\end{array}$} \\
\hline \multirow[b]{2}{*}{ 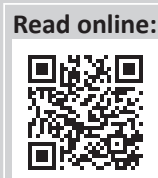 } & \\
\hline & $\begin{array}{l}\text { Scan this QR } \\
\text { code with your } \\
\text { smart phone or } \\
\text { mobile device } \\
\text { to read online. }\end{array}$ \\
\hline
\end{tabular}

\section{Authors:}

Ahmed Loutfy ${ }^{2,3}$

Moustafa T. Saad ${ }^{4}$

Ahmed Soliman Mohamed ${ }^{7}$

Mahmoud Salah ${ }^{7,8}$

of Nursing

Beni-Suef University,

${ }^{3}$ Mohammed Al-Mana

College for Medical Science

${ }^{4}$ Department of

Gerontological Nursing,

Faculty of Nursing, Mansoura

${ }^{5}$ Department of Paediatric

Nursing, Faculty of Nursing,

Mansoura University,

${ }^{6}$ Department of Public Healt and Preventive Medicine,

Faculty of Medicine,

Mansoura University,

${ }^{7}$ Hamad Medical Corporatio

${ }^{8}$ Surgical Specialty Center

(SSC), Doha, Oatar

Ahmed El-Monshed,

ahmed_elmonshed@mans.

edu.eg

mobile device

to read online.
Background: Coronavirus disease 2019 (COVID-19) is a novel sickness that emerged worldwide as an unprecedented crisis and led to major effects on the daily life of the general public as well as negative impacts on their mental well-being.

Aim: This study aimed to assess satisfaction with life and psychological distress during the COVID-19 pandemic in Egypt.

Setting: An online study was conducted in Egypt.

Methods: A cross-sectional online survey was fulfilled by 1056 Egyptian adults from 06 to 13 June 2020. Psychological distress and satisfaction with life were measured by Arabic validated versions of the Kessler Psychological Distress Scale (K10) and the Satisfaction with Life Scale (SWLS).

Results: About half of the surveyed respondents (51\%) were satisfied with their life, whilst $57.4 \%$ experienced severe psychological distress. The independent predictors of satisfaction with life are being married, satisfactory income, low distress, moderate distress and high distress (adjusted odds ratio $[\mathrm{AOR}]=1.2,3.0,2.5,6.9,5.2$ and 2.1, respectively). Being a female, having secondary education, $>$ secondary education, unsatisfactory income and presence of mental illness are the independent predictors of mental distress $(\mathrm{AOR}=2.3,3.9,1.9,1.9,1.6$ and 4.0, respectively).

Conclusion: The study provides evidence about the high prevalence of psychological distress during the peak period of Egypt's COVID-19 pandemic. The study results highlight the enhancement of development interventions to promote psychological well-being and feeling of satisfaction with life during the pandemic.

Keywords: COVID-19; Egypt; life satisfaction; pandemic; psychological distress.

\section{Introduction}

Since December 2019, the novel coronavirus disease 2019 (COVID-19) has spread from Wuhan city to different areas in China and around the world. ${ }^{1}$ On 11 March 2020, the World Health Organization (WHO) declared the COVID-19 outbreak a pandemic. ${ }^{2}$ On 14 February 2020, the Egyptian Ministry of Health reported the first case of COVID-19. To control the COVID-19 outbreak, the Egyptian government introduced preventive and containment measures with a partial closure starting on 25 March. On 31 March, Egypt pronounced 710 COVID-19 cases and 46 related deaths with a mortality rate of $6.48 \%{ }^{3,4}$ As on 06 June 2020, there were 1497 new cases with total cases of 32 612, a total of 1198 deaths and 8538 full recovery. ${ }^{5}$

Generally, several potential stressors were caused by the pandemic that might lead to psychological distress and life dissatisfaction. ${ }^{6}$ Individuals' overall assessments of their psychological wellbeing and quality of life are referred to as life satisfaction. ${ }^{7}$ Psychological distress takes the shape of a negative emotion, which contrasts with life contentment. It refers to people's unfavourable emotional reactions to a number of stimuli, which might include tension, dread, worry and psychological instability. ${ }^{8}$

Fear of contracting COVID-19 and the implications for oneself or loved ones might be potential stressors linked to the virus. The measure taken to prevent the spread of the virus have a

Dates: Received: 10 Jan. 2021 | Accepted: 03 Dec. 2021 | Published: 31 Jan. 2022

How to cite this article: El-Monshed AH, Loutfy A, Saad MT, et al. Satisfaction with life and psychological distress during the COVID-19 pandemic: An Egyptian online cross-sectional study. Afr J Prm Health Care Fam Med. 2022;14(1), a2896. https://doi.org/10.4102/phcfm. v14i1.2896

Copyright: ( 2 2022. The Authors. Licensee: AOSIS. This work is licensed under the Creative Commons Attribution License. 
number of drawbacks, including social isolation, economic costs, disruption of people's work and lifestyles and anxiety about the future. As a result, it is reasonable to expect a rise in psychological discomfort and negative implications for the mental health of vast populations throughout the world. ${ }^{9,10}$

Several early studies provided evidence regarding psychological distress in the context of the COVID-19 pandemic. According to an online survey of the general public in China, more than over half of those polled assessed the psychological impact of the events as moderate-to-severe, with $16.5 \%$ reporting depressed symptoms and $28.8 \%$ reporting anxiety symptoms. ${ }^{1}$ In a follow-up survey 4 weeks later, these proportions appeared to be rather steady, with no substantial reduction in those symptoms. ${ }^{11}$

Another study looking at the emotional indicators before and after the declaration of COVID-19 found that negative emotions increased, whilst the scores of positive emotions and life satisfaction decreased..$^{12}$

Studies investigating the psychological effects of prior epidemics or pandemics such as the Ebola epidemic in $2014^{13,14}$ or the severe acute respiratory syndrome (SARS) outbreak in $2003,{ }^{15}$ found that they were linked to significant psychological discomfort and mental health problems. Given that the COVID-19 pandemic brought additional obstacles for patients, it was suggested that psychiatric nursing interventions be re-adapted to address COVID-19related concerns as well. Fear, worry and uncertainty about one's own and the health of one's family escalated as a result of the pandemic. Furthermore, COVID-19 exposed people to their own and others' suffering and some of them experienced terrible events and there were the unfortunate ones who lost their lives as a result of the pandemic. Furthermore, patients and caregivers were not permitted to interact in person. ${ }^{16}$

Educative interventions supplied patients (and carers during the calls) with up-to-date and realistic information about the coronavirus disease as a first step in the COVID-related mental nursing intervention. During the pandemic, patients with anxiety and acute stress symptoms were given individual relaxation methods such as muscle relaxation, body scan, breath control and creative relaxation. ${ }^{17}$ Irrational beliefs and maladaptive interpretations were challenged and modified through cognitive restructuring. ${ }^{18}$

Given the novelty of the COVID-19 pandemic, the precautionary measures implemented to contain the spread of the disease, and the lack of published research regarding the coronavirus in Egypt, it was important to highlight whether the COVID-19 pandemic had affected life satisfaction of the Egyptian people and has caused psychological distress as an initial step for proposing nursing interventions for the people.

\section{Research design and method Study design}

A cross-sectional online survey was conducted within the predictable peak (one week from 06 to 13 June 2020) month of the COVID-19 outbreak in Egypt.

\section{Setting}

This study was conducted in Egypt, a densely populated country (approximately more than 100 millions inhabitants in 2020). Internet is now available with considerable connectivity and availability and is used extensively by educated people of all ages. Many studies were performed online because of the COVID-19 lockdown and people are familiar with this method of data collection.

\section{Population and sampling strategy}

The target population included adults (18 years and above) in all regions of Egypt who were willing to participate in the study. The study adopted an online survey and the study population may not reflect the actual pattern of the general population. Sample size was calculated using Medcalc 15.8 (https:/ / www. medcalc.org/). The primary outcome of interest is the percentage of people with satisfaction with life. An internal pilot study on 100 subjects found that $51.0 \%$ of them were satisfied with their life. With Alpha error of $5.0 \%$, the study power of $90.0 \%$ and $5.0 \%$ precision, the sample size is 1047 subjects.

\section{Tools and data collection}

Data were collected anonymously through an online semistructured Arabic questionnaire created using Google Forms ${ }^{\mathrm{TM}}$, with a valid link for one week and comprised three parts including a consent form for all respondents.

\section{Socio-demographic and personal characteristics}

Characteristics included gender, age, marital status, having children, governorate, residence, level of education, employment status, number of family members, household income, presence of any chronic diseases, presence of any psychiatric disorders in any family member or one of the respondents' friends, relatives or neighbours who were infected with COVID-19 and what are the sources of the respondents' knowledge regarding COVID-19.

\section{The Kessler Psychological Distress Scale (K10)}

A 10-item 5-point scale (10-50 score) is a self-report questionnaire used for measuring the levels of psychological distress. ${ }^{19}$ The respondents choose the most relevant response for them in the last 4 weeks. After summing scores, the range of 10-15, 16-21, 22-29 and 30-50 represent low, moderate, high and very high psychological distress, respectively. ${ }^{20}$ It was reported that the reliability of K10 was high with Cronbach's alpha of $0.93 .{ }^{21}$ Besides another study stated that the internal consistency of Arabic K10 was also high with Cronbach's alpha of $0.88 .^{22}$ 


\section{Satisfaction with Life Scale}

A self-report questionnaire intended to determine the level of satisfaction with life composed of 5-item rated on 7-point scale. ${ }^{23}$ After summing scores, the range of 5-9, 10-14, 15-19, 21-25, 26-30 and above 31 reflect extremely dissatisfied, dissatisfied, slightly dissatisfied, slightly satisfied, satisfied and extremely satisfied with life, respectively. A score of 20 reflects the impartial point on the scale. The Satisfaction with Life Scale (SWLS) has good internal consistency (Cronbach's alpha $=0.80) .{ }^{24}$ The Arabic version of SWLS was used in the present study with overall good internal consistency (Cronbach's alpha $=0.79$ and test-retest reliability of 0.83$).{ }^{25}$

\section{Procedure}

In Egypt, the government restrictions implemented to decrease the spread of COVID-19 through banning gatherings held up the study all over the country, therefore a web-based survey was required. The obscure online survey link was sent through emails and shared on two of the most commonly used social networking sites (Facebook and WhatsApp) within one week (06 to 13 June 2020). The authors asked respondents to send the survey to their friends and family (snowball technique). The average completion time of the survey was 5-8 $\mathrm{min}$.

\section{Data analysis}

Data were analysed using the Statistical Package for the Social Science (SPSS) version 23. Categorical variables were presented as numbers and percentages. Chi-square was used to test for significant differences between groups. Crude odds ratio (COR) and their 95\% confidence intervals (95\% CI) were calculated. Factors significantly associated with satisfaction with life and severe psychological distresses were entered into a multivariate logistic regression model using the Wald stepwise forward method. Adjusted odds ratio (AOR) and their 95\% CI were calculated. A value of $p \leq 0.05$ was considered statistically significant.

\section{Ethical considerations}

Ethical approval was obtained from the Research Ethics Committee of Faculty of Nursing, Mansoura University (reference number: P.0200). Thereafter, the population fulfilling the eligibility criteria and having filled the informed consent, could open the link and participate in the study. No monetary rewards were given for completing the questionnaire.

\section{Results}

Table 1 shows that participants with older age, married, having children, those employed, family size less than five members and satisfactory family income are associated with higher likelihood of satisfaction with life $(\mathrm{COR}=1.9,4.5,1.7$, $1.9,1.4$ and 2.5, respectively). Being a female, divorced/ widowed, completed at least a secondary education and with unsatisfactory family income, increases the likelihood of a
TABLE 1: Prevalence of satisfaction with life and severe psychological distress amongst study participants and their variation with the socio-demographic factors.

\begin{tabular}{|c|c|c|c|c|c|c|c|c|c|}
\hline \multirow{2}{*}{$\begin{array}{l}\text { Socio- } \\
\text { demographic } \\
\text { factors }\end{array}$} & \multirow[t]{2}{*}{ Total } & \multicolumn{4}{|c|}{ Satisfaction with life } & \multicolumn{4}{|c|}{ Severe distress } \\
\hline & & $n$ & $\%$ & COR & $95 \% \mathrm{Cl}$ & $n$ & $\%$ & COR & $95 \% \mathrm{Cl}$ \\
\hline Overall & 1056 & 359 & 51.0 & - & - & 606 & 57.4 & - & - \\
\hline \multicolumn{10}{|l|}{ Age (years) } \\
\hline$<20$ & 88 & 36 & 40.9 & 1 & $r$ & 55 & 62.5 & 1.4 & $0.8-2.2$ \\
\hline $20-29$ & 687 & 343 & 49.9 & 1.4 & $0.9-2.3$ & 396 & 57.6 & 1.1 & $0.8-1.5$ \\
\hline $30>$ & 281 & 160 & $56.9 * *$ & 1.9 & $1.2-3.1$ & 155 & 55.2 & 1 & $r$ \\
\hline \multicolumn{10}{|l|}{ Gender } \\
\hline Male & 282 & 144 & 51.1 & 1 & $r$ & 118 & 41.8 & 1 & $r$ \\
\hline Female & 774 & 395 & 51.0 & 0.99 & $0.8-1.3$ & 488 & $63.0 * * *$ & 2.4 & $1.8-3.1$ \\
\hline \multicolumn{10}{|l|}{ Marital status } \\
\hline Single & 647 & 291 & $45.0^{*}$ & 2.0 & $1.1-4.1$ & 364 & 56.3 & 1 & $r$ \\
\hline Married & 367 & 236 & $64.3^{* * *}$ & 4.5 & $2.2-9.1$ & 206 & 56.1 & 0.99 & $0.8-1.3$ \\
\hline $\begin{array}{l}\text { Widow/ } \\
\text { divorced }\end{array}$ & 42 & 12 & 28.6 & 1 & $r$ & 36 & $85.7 * * *$ & 4.7 & $1.9-11.2$ \\
\hline \multicolumn{10}{|l|}{ Having children } \\
\hline No & 697 & 325 & 46.6 & 1 & $r$ & 392 & 56.2 & 1 & $r$ \\
\hline Yes & 359 & 214 & $59.6 * * *$ & 1.7 & $1.3-2.2$ & 214 & 59.6 & 1.1 & $0.9-1.5$ \\
\hline \multicolumn{10}{|l|}{ Residence } \\
\hline Urban & 564 & 302 & 53.5 & 1 & $r$ & 324 & 57.4 & 1 & $r$ \\
\hline Rural & 492 & 237 & 48.2 & 0.8 & $0.6-1.0$ & 282 & 57.3 & 1.0 & $0.8-1.3$ \\
\hline \multicolumn{10}{|c|}{ Geographic region } \\
\hline Lower Egypt & 652 & 328 & 50.3 & 1 & $r$ & 384 & 58.9 & 1 & $r$ \\
\hline Frontiers & 115 & 65 & 56.5 & 1.3 & $0.8-1.9$ & 75 & 65.2 & 1.3 & $0.9-2.0$ \\
\hline Upper Egypt & 289 & 146 & 50.5 & 1.0 & $0.8-1.3$ & 147 & 50.9 & 0.7 & $0.5-1$ \\
\hline \multicolumn{10}{|l|}{ Education } \\
\hline$<2$ years & 123 & 73 & $59.3 *$ & 1.6 & $1.1-2.4$ & 55 & 44.7 & 1 & $r$ \\
\hline 2 years & 616 & 313 & 50.8 & 1.1 & $0.8-1.5$ & 365 & $59.3 * *$ & 1.8 & $1.2-2.7$ \\
\hline$>2$ years & 317 & 153 & 48.3 & 1 & $r$ & 186 & $58.7^{* *}$ & 1.8 & $1.2-2.9$ \\
\hline \multicolumn{10}{|l|}{ Occupation } \\
\hline Private work† & 277 & 147 & $53.1^{*}$ & 1.3 & $1.1-1.8$ & 148 & 53.4 & 1 & $r$ \\
\hline Employee & 178 & 108 & $60.7 * *$ & 1.9 & $1.3-2.6$ & 101 & 56.7 & 1.1 & $0.8-1.7$ \\
\hline $\begin{array}{l}\text { Housewife/ } \\
\text { other }\end{array}$ & 174 & 90 & 51.7 & 1.3 & $0.9-1.8$ & 99 & 56.9 & 1.2 & $0.8-1.7$ \\
\hline Students & 427 & 194 & 45.4 & 1 & $r$ & 250 & 60.4 & 1.2 & $0.9-1.7$ \\
\hline \multicolumn{10}{|l|}{ Family size } \\
\hline$<5$ & 425 & 236 & $55.5 * *$ & 1.4 & $1.1-1.7$ & 246 & 57.9 & 1 & $r$ \\
\hline $5>$ & 631 & 303 & 48.0 & 1 & $r$ & 360 & 57.1 & 1.0 & $0.8-1.2$ \\
\hline \multicolumn{10}{|l|}{ Family income } \\
\hline Satisfactory & 789 & 448 & $56.8^{* * *}$ & 2.5 & $1.9-3.4$ & 429 & 54.4 & 1 & $r$ \\
\hline Unsatisfactory & 267 & 91 & 34.1 & 1 & $r$ & 177 & $66.3 * * *$ & 1.7 & $1.2-2.2$ \\
\hline
\end{tabular}

COR, crude odds ratio; $\mathrm{Cl}$, confidence interval; $r$, reference category.

$*, * *, * * *$, Significant difference compared with the reference category at $\leq 0.05, \leq 0.01$ and $\leq 0.001$, respectively.

$\dagger$, Work in the private sector and not affiliated with the government sector.

severe degree of psychological distress $(\mathrm{COR}=2.4,4.7,1.8$, 1.8 and 1.7 , respectively).

As presented in Table 2, the absence of mental illness, having no friends infected with COVID-19, low psychological distress, moderate psychological distress and high psychological distress are associated with increased satisfaction with life $(\mathrm{COR}=2.1,1.3,7.0,5.1$ and 2, respectively). Having a mental illness is associated with a more severe degree of distress $(\mathrm{COR}=3.8)$.

The multivariate logistic regression analysis presented in Table 3 revealed that the independent predictors of life satisfaction are being married, satisfactory income, low distress, moderate distress and high psychological distress 
TABLE 2: Prevalence of satisfaction with life and severe psychological distress amongst study participants and their variation with the clinical and menta factors.

\begin{tabular}{|c|c|c|c|c|c|c|c|c|c|}
\hline \multirow{2}{*}{$\begin{array}{l}\text { Clinical and } \\
\text { mental } \\
\text { factors }\end{array}$} & \multirow[t]{2}{*}{ Total } & \multicolumn{4}{|c|}{ Satisfaction with life } & \multicolumn{4}{|c|}{ Severe distress } \\
\hline & & $n$ & $\%$ & COR & $95 \% \mathrm{Cl}$ & $n$ & $\%$ & COR & $95 \% \mathrm{Cl}$ \\
\hline \multicolumn{10}{|c|}{ Chronic diseases } \\
\hline No & 955 & 486 & 50.9 & 1 & $r$ & 542 & 56.8 & 1 & $r$ \\
\hline Yes & 101 & 53 & 52.5 & 1.1 & $0.7-1.6$ & 64 & 63.4 & 1.3 & $0.9-2.0$ \\
\hline \multicolumn{10}{|c|}{ Mental illness } \\
\hline No & 992 & 517 & $52.1 * * *$ & 2.1 & $1.2-3.5$ & 553 & 55.7 & 1 & $R$ \\
\hline Yes & 64 & 22 & 34.4 & 1 & $r$ & 53 & $82.8 * * *$ & 3.8 & $2.0-7.4$ \\
\hline \multicolumn{10}{|c|}{ Family member infected } \\
\hline No & 1034 & 526 & 50.4 & 1 & $r$ & 591 & 57.2 & 1 & $r$ \\
\hline Yes & 22 & 13 & 59.1 & 1.4 & $0.6-3.3$ & 15 & 68.2 & 1.6 & $0.6-4.0$ \\
\hline \multicolumn{10}{|c|}{ Infected friend } \\
\hline No & 732 & 389 & $53.1 *$ & 1.3 & $1.1-1.7$ & 709 & 55.9 & 1 & $R$ \\
\hline Yes & 324 & 150 & 46.3 & 1 & $R$ & 197 & 60.8 & 1.2 & $0.9-1.6$ \\
\hline \multicolumn{10}{|c|}{ Psychological distress } \\
\hline Low & 197 & 146 & $74.1 * * *$ & 7.0 & $4.7-10.7$ & - & - & - & - \\
\hline Moderate & 253 & 171 & $67.6 * * *$ & 5.1 & $3.6-7.3$ & - & - & - & - \\
\hline High & 282 & 128 & $45.4 * * *$ & 2.0 & $1.4-2.8$ & - & - & - & - \\
\hline Very high & 324 & 94 & 29.0 & 1 & $r$ & - & - & - & - \\
\hline
\end{tabular}

COR, crude odds ratio; $\mathrm{Cl}$, confidence interval; $r$, reference category.

$*, * *, * * *$, Significant difference compared with the reference category at $\leq 0.05, \leq 0.01$ and $\leq 0.001$, respectively.

$(\mathrm{AOR}=1.2,3.0,2.5,6.9,5.2$ and 2.1, respectively). Being a female, having secondary education, $>$ secondary education, unsatisfactory income and presence of mental illness are the independent predictors of psychological distress with AOR of $2.3,3.9,1.9,1.9,1.6$ and 4.0 , respectively.

\section{Discussion}

Any massive pandemic will have a negative impact on the community. Individuals respond to major infectious disease pandemic emotionally and display high levels of uncertainty and distress. ${ }^{26}$ The results of this study indicate that around half $(51.0 \%)$ of the surveyed respondents were satisfied with their life whilst $57.4 \%$ of them experienced severe psychological distress. Plausible explanations could be that this study was conducted within the peak month of Egypt's COVID-19 outbreak. In an epidemic, people display common stress reactions such as fear of getting ill and passing away, fear of being ill and dying, fear of being unable to work during isolation, fear of being fired from their job and losing their money, dread of being quarantined, feeling powerless to protect their family and fear of loved ones dying as a result of the virus. ${ }^{11}$ Because possibilities to communicate face-to-face socially are limited during lockdown, subjective sentiments of loneliness have increased dramatically. ${ }^{27}$

Indeed, the pandemic is associated with an especially high toll when it comes to how individuals feel about their social relationships and their health with reports of loneliness and depression doubling, tripling or even quintupling over the prior known rates. ${ }^{28}$ Egyptian government imposed preventive measures including closing the borders, establishing a state of emergency accompanied by a curfew from 20:00 to 06:00, ban on all gatherings, closing of schools and universities, which had a strong impact on daily
TABLE 3: Multivariable logistic regression analysis of independent predictors of satisfaction with life and severe distress.

\begin{tabular}{|c|c|c|c|c|c|c|c|c|}
\hline \multirow{2}{*}{$\begin{array}{l}\text { Independent } \\
\text { predictors }\end{array}$} & \multicolumn{4}{|c|}{ Satisfaction with life } & \multicolumn{4}{|c|}{ Severe distress } \\
\hline & $\beta$ & $p$ & AOR & $95 \% \mathrm{Cl}$ & $\beta$ & $p$ & AOR & $95 \% \mathrm{Cl}$ \\
\hline \multicolumn{9}{|l|}{ Gender } \\
\hline Male & - & - & - & - & - & $\leq 0.001$ & 1 & $r$ \\
\hline Female & - & - & - & - & 0.8 & - & 2.3 & $1.7-3.1$ \\
\hline \multicolumn{9}{|l|}{ Marital status } \\
\hline Single & 0.1 & 0.7 & 1.2 & $0.5-2.5$ & 0.02 & 0.8 & 1 & $r$ \\
\hline Married & 1.1 & 0.005 & 3.0 & $1.4-6.4$ & 1.4 & 0.003 & 1.0 & $0.8-1.3$ \\
\hline Widow/divorced & - & - & 1 & $r$ & - & - & 3.9 & $1.6-9.7$ \\
\hline \multicolumn{9}{|l|}{ Education } \\
\hline$<$ Secondary & - & - & - & - & - & - & 1 & $r$ \\
\hline Secondary & - & - & - & - & 0.7 & 0.002 & 1.9 & $1.3-2.9$ \\
\hline > Secondary & - & - & - & - & 0.7 & 0.004 & 1.9 & $1.2-3.0$ \\
\hline \multicolumn{9}{|l|}{ Family income } \\
\hline Satisfactory & 0.9 & $\leq 0.001$ & 2.5 & $1.8-3.5$ & 0.5 & 0.001 & 1 & $r$ \\
\hline Unsatisfactory & - & - & 1 & $r$ & - & - & 1.6 & $1.2-2.2$ \\
\hline \multicolumn{9}{|l|}{ Mental illness } \\
\hline No & - & - & - & - & - & $\leq 0.001$ & 1 & $r$ \\
\hline Yes & - & - & - & - & 1.4 & - & 4.0 & $2.0-7.8$ \\
\hline \multicolumn{9}{|c|}{ Psychological distress } \\
\hline Low & 1.9 & $\leq 0.001$ & 6.9 & $4.6-10.5$ & - & - & - & - \\
\hline Moderate & 1.7 & $\leq 0.001$ & 5.2 & $3.6-7.6$ & - & - & - & - \\
\hline High & 0.9 & $\leq 0.001$ & 2.1 & $1.5-2.9$ & - & - & - & - \\
\hline Very high & - & - & 1 & $r$ & - & - & - & - \\
\hline
\end{tabular}

Note: Constant: satisfaction with life $=-2.1$, severe distress $=-1.1$; Model $\chi^{2}$ : satisfaction with life $=216.8$ and $p \leq 0.001 ;$ Model $\chi^{2}$ : severe distress $=91.3, p \leq 0.001 ; \%$ correctly predicted: satisfaction with life $=71.0$, satisfaction with life $=63.6$.

$\mathrm{AOR}$, adjusted odds ratio; $\mathrm{Cl}$, confidence interval; $r$, reference category.

workers, commerce, crafts and the informal sector. Under these circumstances, the COVID-19 pandemic has a strong negative impact on happiness and life satisfaction and in turn, people often experienced high levels of psychological distress.

Prior research had demonstrated immediate negative emotional impact in response to the COVID-19 pandemic. ${ }^{1,12,29,30,31,32}$ An Egyptian study suggested that 23.9\% of the respondents experienced a mild level of psychological impact, whilst 52.0\% demonstrated moderate and severe levels of psychological impact. ${ }^{29}$ In addition, lower rates were demonstrated in an Italian study but in the early stage of the pandemic which found that only $38 \%$ of the Italian population displayed degrees of psychological distress after short exposure to the pandemic. ${ }^{30}$ Besides, a nationwide study conducted during the COVID-19 pandemic on approximately 52000 participants from 36 Chinese provinces revealed that about $35.0 \%$ of the participants had psychological distress. ${ }^{31}$

In April 2020, an international online research conducted in seven languages found that before the lockdown more than $60 \%$ of respondents agreed to be content with their lives, whereas just $30 \%$ agreed during the lockdown. The total score on life satisfaction assessments dropped by $16 \%$, with more individuals feeling unsatisfied 'during' the lockdown period than 'before'. ${ }^{33}$ In a similar line, Chinese research showed that COVID-19's social distancing tactics resulted in lower life satisfaction and increased sadness. ${ }^{10}$ 
On studying the associations between the respondents' socio-demographic factors and the studied measures, the study results showed that being a female increased the likelihood of a severe degree of distress. According to a previous study females, on average, are more prone to loneliness, anxiety and depression than males. ${ }^{34}$ This might be because females are more sensitive emotionally. These results concurs with prior research studies, which showed that females are, to a certain degree, more vulnerable to experience psychological distress during the COVID-19 pandemic. ${ }^{1,29,30,35}$ By contrast, a cross-sectional survey in China that studied the effect of the COVID-19 outbreak on local residents' psychological well-being found that there was not any association between gender and psychological well-being. ${ }^{36}$

People whose level of education was more than secondary school were most likely to experience higher levels of psychological distress, probably because of their high selfawareness of the COVID-19 pandemic and of their health. A similar result was reported in a Chinese study, which found that highly educated people had higher rates of distress. ${ }^{31}$

As financial concerns have an important role in several decisions of daily life, they are likely to cause recurrent or consistent daily hassles. In line with this, we found that unsatisfactory income in this study population was significantly associated with high scores of psychological distress and low scores of life satisfaction.

These results indicated that individuals who are more satisfied with their life changes during the COVID-19 pandemic were less distressed and vice versa. Maybe these individuals had the ability to rationalise or justify their inactive lifestyles and adapt effectively with social distancing measures and then became less frustrated by the restrictive measures during the pandemic. There is no doubt that during a life crisis, people need to rearrange their priorities and to create major behavioural readjustments in their daily lifestyle. ${ }^{37}$ Overloads of such changes because of the COVID-19 pandemic during short periods of time may have severe burdens on individuals' adjustment abilities and then affect their psychological wellbeing. In addition, financial problems caused by the COVID-19 pandemic severely limit people's life options and develop a feeling of fear and uncertainty for them, their families, and their current and future prospects.

In general, growing literature has documented that high degrees of satisfaction with life are associated with high physical and psychological well-being and various aspects of high social and cognitive functioning. ${ }^{38,39,40}$ This results from this study are in agreement with those reported by Zhang et al. who confirmed that people who were more satisfied with their life changes suffered less distress during the COVID-19 pandemic. ${ }^{10}$ Moreover, in Turkey, another study demonstrated that the fear of COVID-19 negatively correlated with life satisfaction. ${ }^{41}$ In addition, results of a study on 317 respondents who participated during the beginning of the dynamic increase of the outbreak in Poland mentioned that anxiety and COVID-19 stress were negatively associated with life satisfaction. ${ }^{42}$

\section{Limitations of the study}

Despite the study's relevance and merits, such as the timing of data collection during Egypt's COVID-19 peak, it had significant flaws. Firstly, the study used an online survey because of the restricted resources available and the COVID-19 pandemic's temporal sensitivity and the study population did not reflect the general population's true pattern. Secondly, the study's fundamental nature, such as the sample approach being limited to persons with internet access, may limit generalisability because of the difficulties of contacting people who do not utilise network devices or who are unable to read and write. Finally, there was selection bias because of oversampling of a certain network of responders (e.g. respondents aged between 20 and 29 years, females, respondents from lower Egypt).

\section{Conclusion}

In conclusion, this study demonstrates the significant incidence of psychological distress during Egypt's COVID-19 pandemic's expected peak phase. During the pandemic, this research raises some serious issues regarding life satisfaction. Conducting a prospective research on vulnerable populations such as children, the elderly and the uneducated will be beneficial. In addition, to avoid additional psychosocial issues and reduce psychological distress, a complete crisis prevention and intervention system should be developed, which includes epidemiological surveillance, screening, referral and focused intervention. Furthermore, national strategic planning and coordination for psychological first aid during large-scale pandemics should be established, with a focus on women. The findings of the study also imply that programmes aimed at enhancing psychological wellbeing in the general population should be developed quickly, taking into account people's individual features and histories. Finally, longitudinal studies should be used in the future to uncover protective and risk variables for psychological distress during post-epidemic periods.

\section{Acknowledgements}

The authors would like to acknowledge and thank all participants in this study for their valuable time.

\section{Competing interests}

The authors declare that they have no financial or personal relationships that may have inappropriately influenced them in writing this article.

\section{Authors' contributions}

A.H. El., A-H.E-G., A.L., M.Z., M.T.S. and A.S.A. conceived and designed the study. M.T.S., A.S.M., and M.S. conducted 
the literature review. A.H.El. designed the questionnaire. A.S.A., A.S.M., and M.S. collected the data through online survey. M.Z. and A.H.E-G. analysed and interpreted data. A.H.El., A.L., M.Z., M.T.S. and A.S.A. drafted the manuscript. A.H.El. and A-H.E-G., critically revised the manuscript. All authors approved the final manuscript before submission.

\section{Funding information}

This research received no specific grant from any funding agency in the public, commercial or not-for-profit sectors.

\section{Data availability}

Data are available upon request from the corresponding author, A-H.E-G.

\section{Disclaimer}

The views and opinions expressed in this article are those of the authors and do not necessarily reflect the official policy or position of any affiliated agency of the authors.

\section{References}

1. Wang C, Pan R, Wan X, et al. Immediate psychological responses and associated factors during the initial stage of the 2019 coronavirus disease (COVID-19) epidemic among the general population in China. Int J Environ Res Public Health. 2020;17(5):1729. https://doi.org/10.3390/ijerph17051729

2. Shi Y, Wang J, Yang Y, et al. Knowledge and attitudes of medical staff in Chinese psychiatric hospitals regarding COVID-19. Brain Behav Immun Heal. 2020;4:100064. https://doi.org/10.1016/j.bbih.2020.100064

3. Hassany M, Abdel-Razek W, Asem N, AbdAllah M, Zaid H. Estimation of COVID-19 burden in Egypt. Lancet Infect Dis. 2020;20(8):896-897. https://doi.org/10.1016/ S1473-3099(20)30319-4

4. El-Monshed AH, Amr M, Ali AS, Elmasry YM, Zoromba M. Nurses' knowledge concerns, perceived impact and preparedness toward COVID-19 pandemic: A cross-sectional survey. Int J Nurs Pract. 2021;27(6):13017. https://doi. org/10.1111/ijn.13017

5. Egyptian Ministry of Health. The COVID-19 Egyptian statistics [homepage on the Internet]. 2020 [cited 2020 June 6]. Available from: https://www.care.gov.eg/ EgyptCare/Index.aspx

6. Inter-Agency Standing Committee. Briefing note on addressing mental health and psychosocial aspects of COVID-19 outbreak [homepage on the Internet]. Version 1.1. 2020 [cited 2020 June 6]. Available from: https://pscentre.org/wp-content/ uploads/2020/02/MHPSS-in-nCoV-2020_ENG-1.pdf

7. Schroder HS, Dawood S, Yalch MM, Donnellan MB, Moser JS. The role of implicit theories in mental health symptoms, emotion regulation, and hypothetica treatment choices in college students. Cognit Ther Res. 2015;39(2):120-139. https://doi.org/10.1007/s10608-014-9652-6

8. Brody C, Chhoun P, Tuot S, Pal K, Chhim K, Yi S. HIV risk and psychological distress among female entertainment workers in Cambodia: A cross-sectional study. BMC Public Health. 2016;16(1):133. https://doi.org/10.1186/s12889 016-2814-6

9. Petzold MB, Bendau A, Plag J, et al. Risk, resilience, psychological distress, and anxiety at the beginning of the COVID-19 pandemic in Germany. Brain Behav. 2020;10(9):e01745. https://doi.org/10.1002/brb3.1745

10. Zhang SX, Wang Y, Rauch A, Wei F. Unprecedented disruption of lives and work: Health, distress and life satisfaction of working adults in China one month into the COVID-19 outbreak. Psychiatry Res. 2020;288:112958. https://doi.org/10.1016/j. psychres.2020.112958

11. Wang C, Pan R, Wan X, et al. A longitudinal study on the mental health of general population during the COVID-19 epidemic in China. Brain Behav Immun. 2020;87:40. https://doi.org/10.1016/j.bbi.2020.04.028

12. Li S, Wang Y, Xue J, Zhao N, Zhu T. The impact of covid-19 epidemic declaration on psychological consequences: A study on active weibo users. Int J Environ Res Public Health. 2020;17(6):2032. https://doi.org/10.3390/ijerph17062032

13. Greenberg N, Wessely $S$, Wykes T. Potential mental health consequences for workers in the Ebola regions of West Africa - A lesson for all challenging environments. J Ment Heal. 2015;24(1):1-3. https://doi.org/10.3109/09638237.2 014.1000676

14. Mohammed A, Sheikh TL, Gidado S, et al. An evaluation of psychological distress and social support of survivors and contacts of Ebola virus disease infection and their relatives in Lagos, Nigeria: A cross sectional study-2014. BMC Public Health. 2015;15(1):824. https://doi.org/10.1186/s12889-015-2167-6
15. Maunder RG, Lancee WJ, Balderson KE, et al. Long-term psychological and occupational effects of providing hospital healthcare during SARS outbreak. Emerg Infect Dis. 2006;12(12):1924-1932. https://doi.org/10.3201/eid1212.060584

16. Rossi Ferrario S, Panzeri A, Cerutti P, Sacco D. The psychological experience and intervention in post-acute COVID-19 inpatients. Neuropsychiatr Dis Treat. 2021;17:413-422. https://doi.org/10.2147/NDT.S283558

17. American Psychiatric Association. Citing the DSM V. Diagnostic and statistical manual of mental disorder. 5th ed. Washington, DC: American Psychiatric Association; 2013, p. 280

18. Beck AT. Cognitive therapy and the emotional disorders. New York, NY Penguin; 1979.

19. Kessler R, Mroczek D. An update of the development of mental health screening scales for the US National Health Interview Study. Ann Arbor, MI: Survey Research Center of the Institute for Social Research, University of Michigan; 1992.

20. Andrews $\mathrm{G}$, Slade T. Interpreting scores on the Kessler Psychological Distress Scale (K10). Aust N Z J Public Health. 2001;25(6):494-497. https://doi. (K10). Aust N Z J Public Health.
org/10.1111/j.1467-842X.2001.tb00310.x

21. Fassaert T, De Wit MAS, Tuinebreijer WC, et al. Psychometric properties of an interviewer-administered version of the Kessler Psychological Distress scale (K10) among Dutch, Moroccan and Turkish respondents. Int J Methods Psychiatr Res. 2009;18(3):159-168. https://doi.org/10.1002/mpr.288

22. Easton SD, Safadi NS, Wang Y, Hasson RG. The Kessler psychological distress scale: Translation and validation of an Arabic version. Health Qual Life Outcomes. 2017;15(1):215. https://doi.org/10.1186/s12955-017-0783-9

23. Diener E, Emmons RA, Larsem RJ, Griffin S. The satisfaction with life scale. J Pers Assess. 1985;49(1):71-75. https://doi.org/10.1207/s15327752jpa4901_13

24. Pavot W, Diener E. Review of the satisfaction with life scale. Psychol Assess. 1993;5(2):164-172. https://doi.org/10.1037/1040-3590.5.2.164

25. Abdallah T. The satisfaction with life Scale (SWLS): Psychometric properties in an arabic-speaking sample. Int J Adolesc Youth. 1998;7(2):113-119. https://doi.org/ 10.1080/02673843.1998.9747816

26. Brooks SK, Webster RK, Smith LE, et al. The psychological impact of quarantine and how to reduce it: Rapid review of the evidence. Lancet. 2020;395(10227):912-920. https://doi.org/10.1016/S0140-6736(20)30460-8

27. El-Monshed AH, El-Adl AA, Ali AS, Loutfy A. University students under lockdown, the psychosocial effects and coping strategies during COVID-19 pandemic: A cross sectional study in Egypt. J Am Coll Heal. 2021. https://doi.org/10.1080/07448481. 2021.1891086

28. Boursier V, Gioia F, Musetti A, Schimmenti A. Facing loneliness and anxiety during the COVID-19 isolation: The role of excessive social media use in a sample of Italian adults. Front Psychiatry. 2020;11:586222. https://doi.org/10.3389/fpsyt.2020.586222

29. El-Zoghby SM, Soltan EM, Salama HM. Impact of the COVID-19 pandemic on mental health and social support among adult Egyptians. J Community Health 2020;45:689-695. https://doi.org/10.1007/s10900-020-00853-5

30. Moccia $L$, Janiri $D$, Pepe $M$, et al. Affective temperament, attachment style, and the psychological impact of the COVID-19 outbreak: An early report on the Italian general population. Brain Behav Immun. 2020;87:75-79. https://doi. org/10.1016/j.bbi.2020.04.048

31. Qiu J, Shen B, Zhao M, Wang Z, Xie B, Xu Y. A nationwide survey of psychological distress among Chinese people in the COVID-19 epidemic: Implications and policy
recommendations. Gen Psychiatry. 2020;33(2):e100213. https://doi.org/10.1136/ recommendations. Gen
gpsych-2020-100213

32. Zhai $Y$, Du X. Addressing collegiate mental health amid COVID-19 pandemic. Psychiatry Res. 2020;288:113003. https://doi.org/10.1016/j. psychres.2020.113003

33. AMMAR A, Chtourou $\mathrm{H}$, Boukhris $\mathrm{O}$, et al. Social participation and life satisfaction of peoples during the COVID-19 home confinement: The ECLB-COVID19 multicenter study. medRxiv. 2020. https://doi.org/10.1101/2020.05.05.20091066

34. Cao W, Fang Z, Hou G, et al. The psychological impact of the COVID-19 epidemic on college students in China. Psychiatry Res. 2020;287:112934. https://doi. org/10.1016/j.psychres.2020.112934

35. Mazza C, Ricci E, Biondi S, et al. A nationwide survey of psychological distress among Italian people during the COVID-19 pandemic: Immediate psychologica responses and associated factors. Int J Environ Res Public Health. 2020;17(9):3165. https://doi.org/10.3390/ijerph17093165

36. Zhang Y, Ma ZF. Impact of the COVID-19 pandemic on mental health and quality of life among local residents in Liaoning Province, China: A cross-sectional study. Int J Environ Res Public Health. 2020;17(7):2381. https://doi.org/10.3390/ijerph17072381

37. Moreno C, Wykes T, Galderisi S, et al. How mental health care should change as a consequence of the COVID-19 pandemic. Lancet Psychiatry. 2020;7(9):813-824. https://doi.org/10.1016/S2215-0366(20)30307-2

38. Batthyany A, Russo-Netzer P. Meaning in positive and existential psychology. New York, NY: Springer; 2014

39. Diener E, Biswas-Diener R. Happiness: Unlocking the mysteries of psychological wealth. Malden, MA: Blackwell Publishing; 2008.

40. Seligman MEP. Authentic happiness: Using the new positive psychology to realize your potential for lasting fulfillment. New York, NY: Free Press; 2002.

41. Satici B, Gocet-Tekin E, Deniz ME, Satici SA. Adaptation of the fear of COVID-19 scale: Its association with psychological distress and life satisfaction in Turkey. Int J Men Health Addict. 2020;19:1980-1988. https://doi.org/10.1007/s11469-020-00294-0

42. Trzebiński J, Cabański M, Czarnecka JZ. Reaction to the COVID-19 pandemic: The influence of meaning in life, life satisfaction, and assumptions on world orderliness
and positivity. J Loss Trauma. 2020;25(6-7):544-557. https://doi.org/10.1080/15 and positivity. J Loss Traun
325024.2020.1765098 